\title{
Interocular suppression in normal and amblyopic subjects: The effect of unilateral attenuation with neutral density filters
}

\author{
UTE LEONARDS and RUXANDRA SIRETEANU \\ Max-Planck-Institut für Hirnforschung, Frankfurt, Germany
}

\begin{abstract}
In normal subjects, binocular rivalry suppression takes time to build up (Wolfe, 1986a). The time courses of interocular suppression are different and heterogeneous in amblyopic subjects (de Belsunce \& Sireteanu, 1991). In the present study, we found that, in normal observers, progressive reduction of one eye's stimulus luminance with neutral density filters produces time courses similar to those of amblyopic subjects. Conversely, in amblyopes, attenuation of the dominant eye's stimulus produces time courses similar to those of normal observers. Under conditions of balancing of the two eyes, amblyopes experience alternating suppression, similarly to binocular rivalry of normals.
\end{abstract}

In 1760, DuTour wanted to investigate how we see a single world with two eyes. He was the first to describe the phenomenon of binocular suppression, today well known as binocular rivalry. If, for example, in dichoptic presentation a pattern of vertical lines is presented to the right eye while horizontal lines are shown to the left, some regions of the visual field will be perceived as containing horizontal lines, others as containing vertical lines. There is no fusion of the vertical and horizontal images. The percept changes periodically between dominance and suppression (Blake, 1989; Breese, 1899; Helmholtz, 1867; Levelt, 1965; Panum, 1858).

However, if dichoptically presented stimuli are flashed only briefly, they appear as fused into a single percept (Anderson, Bechtoldt, \& Dunlop, 1978; Bokander, 1966; Bower \& Haley, 1964; Goldstein, 1970; Hering, 1920; Kaufmann, 1963; Wade, 1973). Wolfe (1983) systematically measured the "rise-time" of suppression, which leads to the rivalrous perception in normal subjects. Dichoptic stimuli were perceived as superimposed ("fused") if they were flashed for less than $150 \mathrm{msec}$. In other words, rivalry suppression takes about $150 \mathrm{msec}$ to build up.

It seemed promising to compare this kind of alternating suppression with the constant suppression that occurs in subjects with anomalous binocular vision (strabismus and/or anisometropia). Under binocular viewing conditions, these "constant suppressors" lose parts of their af-

The authors thank Wolf Singer for support of this research and for the critical reading of an earlier version of the manuscript, Maria Fronius for helpful suggestions on the manuscript, Margot Rupp for orthoptic examination of the subjects, Silke Wiemerslage for preparing the illustrations, Helga Reitz for typing of the manuscript, and, especially, all the subjects for their participation in this study. Correspondence should be addressed to R. Sireteanu, Max-Planck-Institut für Hirnforschung, Deutschordenstrasse 46, D-6000 Frankfurt 71, Germany. fected eye's image, probably to avoid visual diplopia and confusion (Duke-Elder \& Wybar, 1973). Wolfe (1986a) compared normal subjects and constant suppressors with unilateral amblyopia under rivalrous conditions. He did not find any differences between the time courses of suppression in observers with normal or abnormal binocular vision. Therefore, in line with other researchers, Wolfe suggested the existence of some similarities in neural mechanisms of constant suppression of amblyopes and rivalry suppression in normals (Dale, 1982; Fahle, 1983; von Noorden, 1990; Wolfe, 1986a).

However, data also point toward a difference between rivalry and constant suppression. To elicit optimal suppression, stimuli of orthogonal orientation should be used in binocular rivalry, whereas stimuli of the same orientation work best for constant suppression (Schor, 1977). The depth of rivalry suppression (the amount by which a suppressed stimulus is below the visibility threshold) is relatively constant across normal observers, but the magnitude of constant suppression across amblyopes varies over more than one log-unit range (Holopigian, Blake, \& Greenwald, 1988). Likewise, the pattern of short wavelength sensitivity loss differs between constant suppression and rivalry suppression (Smith, Levi, Manny, Harwerth, \& White, 1985). These differences suggest that the two suppression phenomena might involve different neural pathways.

De Belsunce and Sireteanu (1991) reexamined these controversial findings by repeating Wolfe's experiments $(1983,1986 a)$ in normal observers and in subjects with known disorders of binocular vision. They found that the temporal properties of suppression in normal and amblyopic subjects differed. A first group of amblyopes, also described by Wolfe (1986a), perceived superimposition of the two monocular images for stimulus durations shorter than $150 \mathrm{msec}$ and suppression for longer lasting stimuli; this was similar to the time pattern for normal observers. 
A second group of amblyopic subjects showed a much more rapid onset of suppression (about $80 \mathrm{msec}$ instead of $150 \mathrm{msec}$ ). A third group perceived only the nonamblyopic eye's image for stimuli shorter than $30 \mathrm{msec}$, partial superimposition for longer lasting stimuli, and suppression for stimulus durations over $1,000 \mathrm{msec}$. From these findings, de Belsunce and Sireteanu concluded that rivalry suppression and constant suppression are based on different mechanisms. They suggested that the loss of visibility of the amblyopic eye's stimulus for short stimulus durations in subjects of their third group might be explained by delayed image processing in the amblyopic visual pathway. Indeed, reaction times and visually evoked cortical potentials are delayed for the amblyopic eye (Haase \& Goossens, 1984; Hamasaki \& Flynn, 1981; von Noorden, 1961; von Noorden \& Burian, 1960). De Belsunce and Sireteanu (1991) verified their hypothesis by showing that it is possible to reproduce the "amblyopic" pattern of suppression in normal subjects by attenuating one eye's image with neutral density filters. These filters produce a reduction in the mean luminance and contrast. They also lead to a temporal delay of the presented stimulus (e.g., the Pulfrich phenomenon).

The aim of the present study was to perform a further test of the suggestions of de Belsunce and Sireteanu (1991). We reasoned that, if the differences in the time courses of the two suppression forms are caused by the weakened (and probably delayed) processing of the amblyopic eye, it should also be possible to balance the two eyes of amblyopes by attenuating the image of the nonamblyopic eye with neutral density filters. Such a stimulus attenuation is known to lead to a decrease of suppression of the amblyopic eye by the nonamblyopic (Awaya, Tanabe, \& Ueda, 1968; Hayashi, 1969; von Noorden \& Leffler, 1966). If this hypothesis is correct, the balancing of the two eyes in amblyopes should result in superimposition of the two images for short stimulus durations. This would indicate whether or not the temporal properties of rivalry and constant suppression are different expressions of one and the same underlying mechanism.

To differentiate between unilateral, constant suppression (presumed to occur in amblyopic subjects) and alternating suppression (as in binocular rivalry), we modified the rating scale used by Wolfe (1986a) and de Belsunce and Sireteanu (1991) by introducing a third graphical axis, which represented the strength of subjective eye dominance. This modification made it necessary to repeat the experiments of de Belsunce and Sireteanu (1991) on a large number of subjects. (Parts of these results have been presented in an abstract; see Leonards \& Sireteanu, 1991.)

\section{METHOD}

\section{Subjects}

We tested two different groups of observers. The first group consisted of 9 normal subjects, 19-45 years of age. All had normal or fully corrected visual acuity (corrected visus 1.0 or more) and had stereopsis of at least $40^{\prime \prime}$, as assessed by the Titmus, the Randot, and the TNO-Test. Eight of these normal observers were naive as to the purpose of the experiment. The 9th was one of the authors of this report.

The second group comprised 10 subjects, 25-54 years of age, with different monocular visual losses (amblyopia due to strabismus and/or anisometropia). In most cases, stereoacuity was also impaired. The results of the orthoptic examination are shown in Table 1 . The subjects were wearing their best correction during testing. When tested monocularly, all amblyopes were able to fully perceive the stimulus presented to their weaker eye. All amblyopes were naive subjects.

Each subject was informed about the experimental procedures; written consent was obtained prior to participation in the study.

\section{Apparatus}

The observers sat in a darkened room at a distance of $114 \mathrm{~cm}$ from a tangent screen, viewing dichoptically presented horizontal and vertical square-wave gratings of circular shape. The stimuli were dissociated by polarizing filters. Projection was simultaneous. Computer-controlled shutters in front of the projectors were used to vary stimulus duration from 10 to $6,000 \mathrm{msec}$. The low luminance (mean luminance $0.8 \mathrm{~cd} / \mathrm{m}^{2}$ ) of the stimuli was dictated by the necessity of complete dissociation by the polarizing filters. The low spatial frequency $(0.5 \mathrm{c} / \mathrm{deg}$ ) and the rather large stimulus field (diameter, $6^{\circ}$ ) were chosen to ensure that the patterns were resolved monocularly even by observers with deep amblyopia (J.KL., S.H.). The stimuli were not masked, since the stimulus did not produce noticeable afterimages and test conditions were intended to be comparable to those of Wolfe (1986a) and de Belsunce and Sireteanu (1991).

\section{Procedure}

Prior to the onset of the experiments, the subjects were adapted to the background luminance of the screen. Then they were asked to wear spectacles with polarizing filters. A dichoptic stimulus was presented for $2 \mathrm{~min}$. The subjects were invited to describe their perception with their own words. Except for R.M. and S.H., who reported perceiving only one grating (presented to the nonamblyopic eye), all the observers saw vertical and horizontal gratings alternating ( = rivalry). This impression was rated " 3 "' on the rating scale, which will be defined later.

To compensate for the "vertical effect" (Sireteanu \& Singer, 1980) of the amblyopic subjects, the vertical grating was presented to the nonamblyopic eye, the horizontal to the amblyopic. In the control experiments, reversing the gratings resulted in strengthening the dominance of the nonamblyopic eye.

Care was taken to ensure that the two physically superimposed stimuli were perceived as superimposed. For only 1 subject with nonharmonious anomalous correspondence (K.R.), who showed diplopia with longer-lasting stimuli, subjective superimposition of the stimuli was achieved by adding prisms in front of the amblyopic eye (the right eye, visus 0.4 ).

The perception of either horizontal or vertical square-wave gratings was rated " 0 ." Then the superimposed gratings were projected simultaneously without polarizing glasses. The perceived "checkerboard" was rated " 5 ." Afterward, the 6-point rating scale was explained: $5=$ checkerboard, $4=$ both orientations seen to equal parts but without crossings (islands of vertical or horizontal gratings), $3=$ rivalry, 2 = one orientation predominant in surface area, $1=$ one orientation predominant even more, $0=$ only one orientation perceived (for ratings 0,1 , or 2 , the subjects also told us the orientation of the grating that dominated). The subjects learned to use the rating scale with little or no difficulty.

Each session comprised one to three training runs and at least six further runs of the 20 different stimulus durations. The durations ranged from 10 to $6,000 \mathrm{msec}$, and the stimuli were presented in random order. Sufficient time was allowed between presentations in order for previously induced suppression to dissipate fully. The stimuli were projected at the center of a large screen $\left(70^{\circ} \times 50^{\circ}\right)$. 


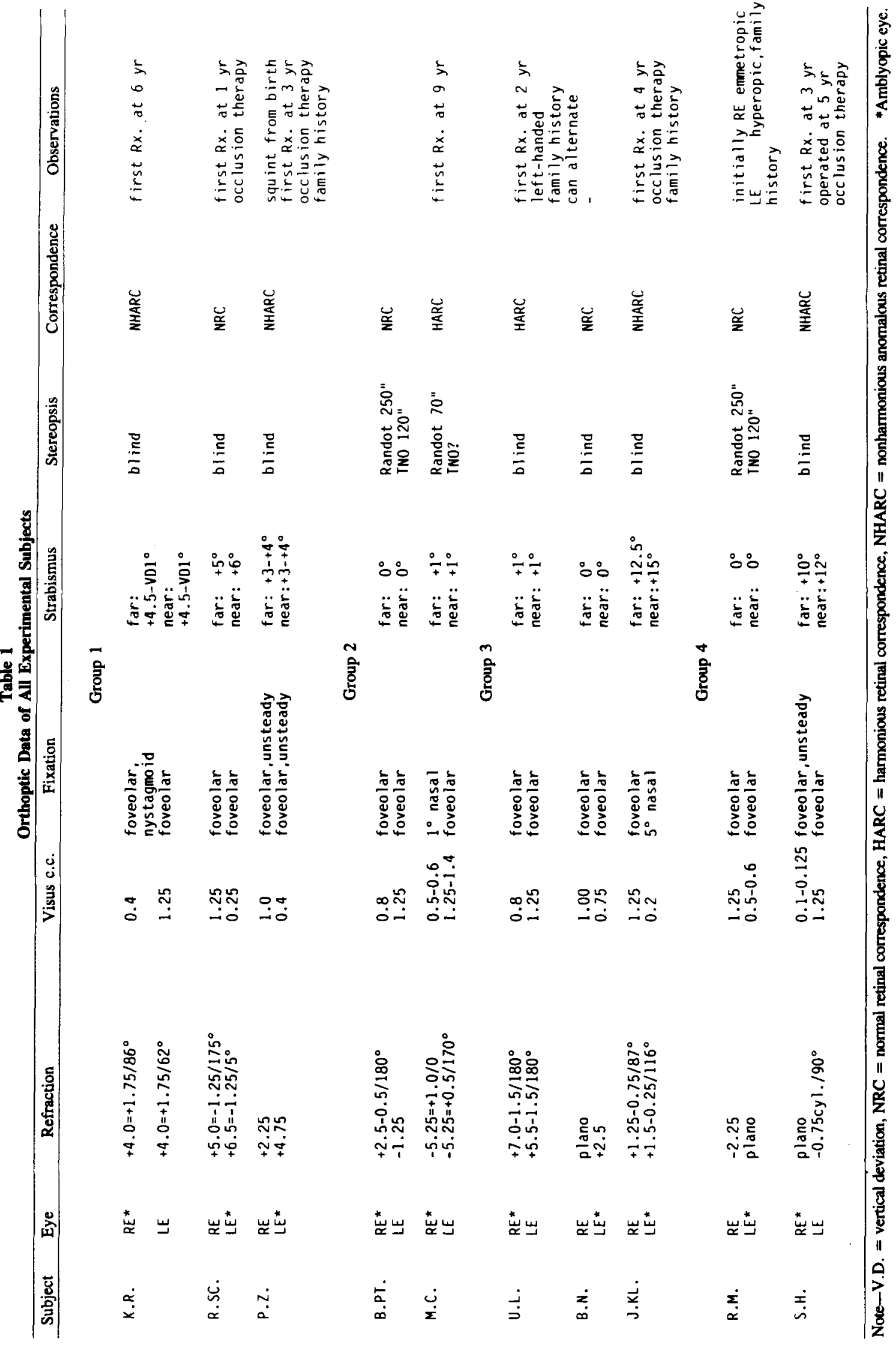




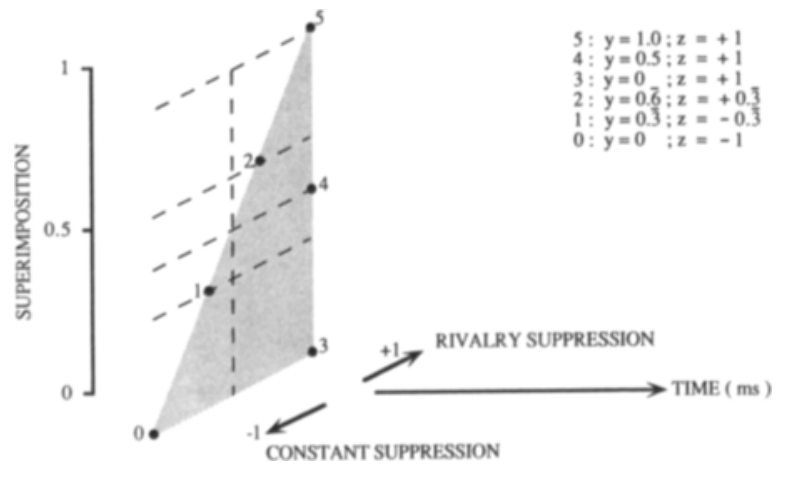

Figure 1. Graphical representation of the normalized rating scale: $x$-axis, presentation time (in milliseconds); $y$-axis, amount of superimposition ( 1 , both eyes' images are seen as superimposed; 0 , only one eye's image is seen); $z$-axis, dominance of the eyes $(+1$, binocular perception, alternation; -1 , monocular perception); the implementation of the $z$-axis allows one to distinguish between constant suppression and rivalry suppression.

The edges of the screen were barely visible and thus could not influence the onset of suppression.

In addition to changes in stimulus duration, it was possible to lower the luminance of one monocular stimulus by introducing different neutral density filters into the light beam. For each eye, the luminance could be decreased from $100 \%$ to $51 \%, 32 \%, 16 \%$, or $6.5 \%$. The filters attenuated the luminance of the stimulus presented to the nondominant eye in normal observers and the nonamblyopic eye in amblyopes.

In the control experiments, the stimulus presented to the second eye (the nondominant eye in normal observers and the amblyopic eye in amblyopic subjects) was attenuated. In this paper, we will refer to "the attenuation of the stimulus of one eye with neutral density filters" as "the attenuation of the eye." This should not implicate a direct physiological attenuation, but rather the reduced contrast and the luminance decrease of the stimulus presented to the eye.

\section{Graphical Representation}

Our rating scale is not continuous: the impression " 3 " for rivalry suppression cannot be interpreted as an intermediate stage between superimposition (= "5") and monocular sensation (= "0"). Superimposition or monocular sensation cannot be interpreted as intermediate stages, either. On the contrary, rivalry suppression and the monocular sensation/constant suppression have to be represented at a similar level according to their analogous phenomenology. To take this into consideration, the graphical scale used by de Belsunce and Sireteanu (1991) was extended by a third axis (see Figure 1). The incorporation of the $z$-axis allowed us to account for similarities between binocular rivalry and constant suppression (presentation at the same level on the $y$-axis) and also to distinguish between them, which is expressed by different $z$-axis deviations. To express the complete dominance of one eye (only the image of one eye is seen; this is constant suppression), the rating of 0 was combined with a $z$-axis deviation of -1 . The decrease in eye dominance was correlated with a $z$-axis deviation of -0.33 for the rating of 1 and +0.33 for the rating of 2 . Ratings of 3,4 , and 5 are characterized by the equivalence of both eyes ( = direction of rivalry suppression). To take this into account, the ratings 3,4 , and 5 were correlated with a $z$-axis deviation of +1 . Stimulus duration (in milliseconds) is plotted on the $x$-axis, and "superimposition" (the amount of simultaneity in the perception of the two gratings) is scaled on the normalized $y$-axis.

In spite of the fact that we used an ordinal scale, means and standard deviations were calculated instead of the more common me- dians and interquartiles. This allows a comparison with the data of Wolfe (1986a) and de Belsunce and Sireteanu (1991), when zaxis deviation is not taken into account.

\section{RESULTS}

\section{Without Neutral Density Filters}

\section{Normal Subjects}

Without attenuation of the stimulus of one eye and for stimulus durations shorter than $30-50 \mathrm{msec}$, all normal observers perceived a checkerboard (superimposition of the orthogonal gratings). Longer stimulus durations led to binocular rivalry and resulted in alternating suppression of one and then the other monocular input (see Figure 2).

\section{Amblyopic Subjects}

With the use of the new graphical representation, the time course of suppression in amblyopes turned out to be more heterogeneous than predicted by the results of Wolfe (1986a) and de Belsunce and Sireteanu (1991). Figure 2 shows the suppression patterns of all tested subjects. The time courses described here appear to belong to a continuous spectrum, rather than forming discrete groups. For reasons of clarity, the classification was specified a posteriori.

Group 1. In 3 subjects (the esotropes K.R. and R.SC., and the anisometropic esotrope P.Z.), the time courses of suppression were similar to those of normal observers. All subjects perceived complete superimposition for stimuli lasting less than 20-30 msec. Stimuli presented longer than $1,000 \mathrm{msec}$ led to binocular rivalry with a slight temporal dominance of the nonamblyopic eye. For stimulus durations between 200 and $1,000 \mathrm{msec}$, the nonamblyopic eye dominated (see Figures 2 and 3).

In contrast to K.R. and R.SC., Subject P.Z. did not show complete alternation from one eye to the other for long stimulus durations. The nonamblyopic eye's image remained visible over the whole presentation time. Thus, in his case, neither binocular rivalry nor constant suppression could be seen, but something in between.

Group 2. Two amblyopes (the small-angle anisometrope B.P. and the microstrabismic esotrope M.C.) did not reach complete superimposition of the monocular gratings, but always exhibited a slight dominance of the nonamblyopic eye for short stimulus presentations. Longlasting stimulus presentation resulted in complete rivalry of the two monocular images (see Figures 2 and 3).

Group 3. Three subjects (the microstrabismic esotrope U.L., the anisometrope B.N., and the large-angle esotrope J.KL.) perceived only the image of the dominant eye for stimuli presented less than $30 \mathrm{msec}$, unstable pattern combinations with a dominance of the nonamblyopic eye for longer lasting stimulus presentations, and rivalry suppression for the longest stimulus durations (see Figures 2 and 3).

Group 4. Only two amblyopic subjects (the anisometrope R.M. and the large-angle esotrope and anisometrope S.H.) showed constant suppression for long stimulus durations. These subjects perceived incomplete superimposi- 


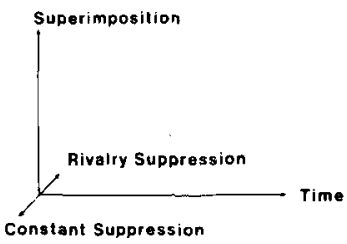

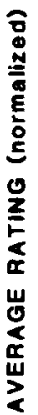

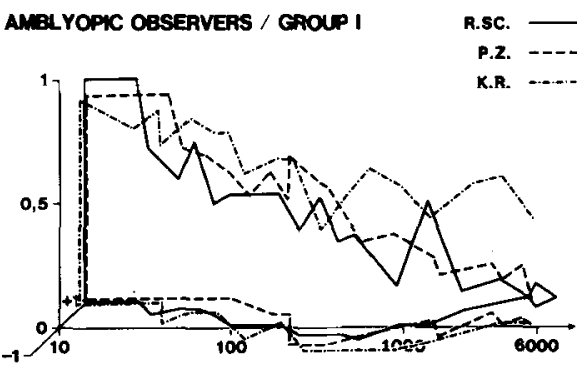

AMBLYOPC OBSERVERS / GROUP

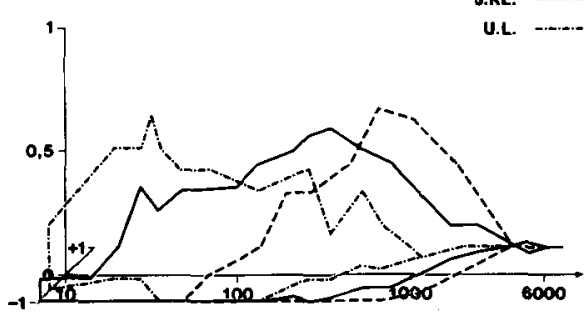

NORIMLL OBSERVERS

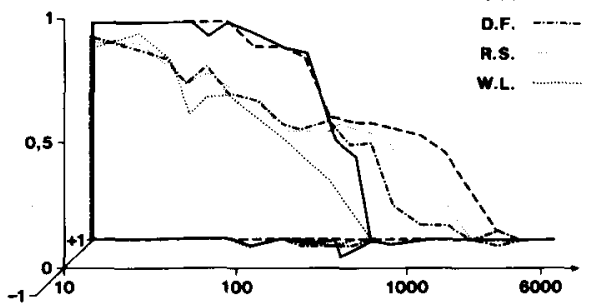

AMBLYPIC OESERVERS / GAOUP I M.c. -

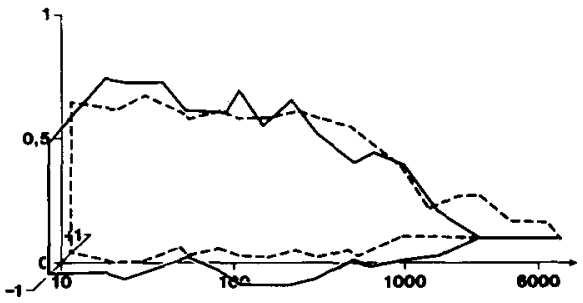

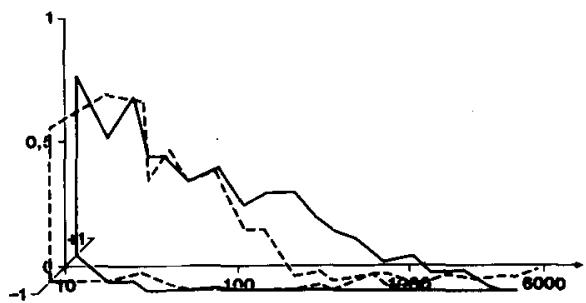

STIMULUS DURATION (ms)

Figure 2. Time course of suppression in normal and amblyopic observers (without neutral density filters). Perception of dichoptically presented orthogonal gratings for stimulus durations ranging from 10 to 6,000 msec. Each point is based on at least six trials. Normal observers: Gratings appeared to be fused for short durations and rivalrous for long durations. Amblyopic observers (Group 1): similar to normal observers; stimulus durations ranging from 200 to 1,000 msec lead to predominance of the nonamblyopic eye; long stimulus durations result in rivalry alternations. Amblyopic observers (Group 2): incomplete superimposition for short stimulus durations with dominance of the nonamblyopic eye; longer stimulus durations result in binocular rivalry. Amblyopic subjects (Group 3): monocular perception of the nonamblyopic eye for short stimulus durations; rivalry for stimuli presented longer than 2,000 msec. Amblyopic subjects (Group 4): gratings appear to be fused for short presentation times; longer stimulus durations result in constant suppression of the amblyopic eye.

tion for stimulus durations less than $500 \mathrm{msec}$, comparable to what was found for the subjects in Group 2. For longer stimulus presentations, the image of the amblyopic eye was totally invisible (suppressed; see Figures 2 and 3).

\section{With Neutral Density Filters}

\section{Normal Subjects}

As shown by de Belsunce and Sireteanu (1991), attenuation of the nondominant eye's image resulted in the progressive loss of visibility of the image corresponding to this eye for short stimulus presentations. For longer lasting stimuli, subjects still reported rivalry suppression with complete alternation between the two inputs, solely the time the image of the attenuated eye was seen alone was shorter than that of the nonattenuated eye. Nevertheless, the onset of rivalry suppression was not delayed by the neutral density filters (see Figure 4). The subjects did not perceive any luminance differences between the two eyes. Attenuation of the dominant eye resulted in a progressive loss of this eye's image, comparable to the results described for the attenuation of the nondominant eye.

\section{Amblyopic Subjects}

Group 1. For very short stimulus durations, the subjects' perception was not influenced by the use of neutral density filters. The subjects still perceived the two 

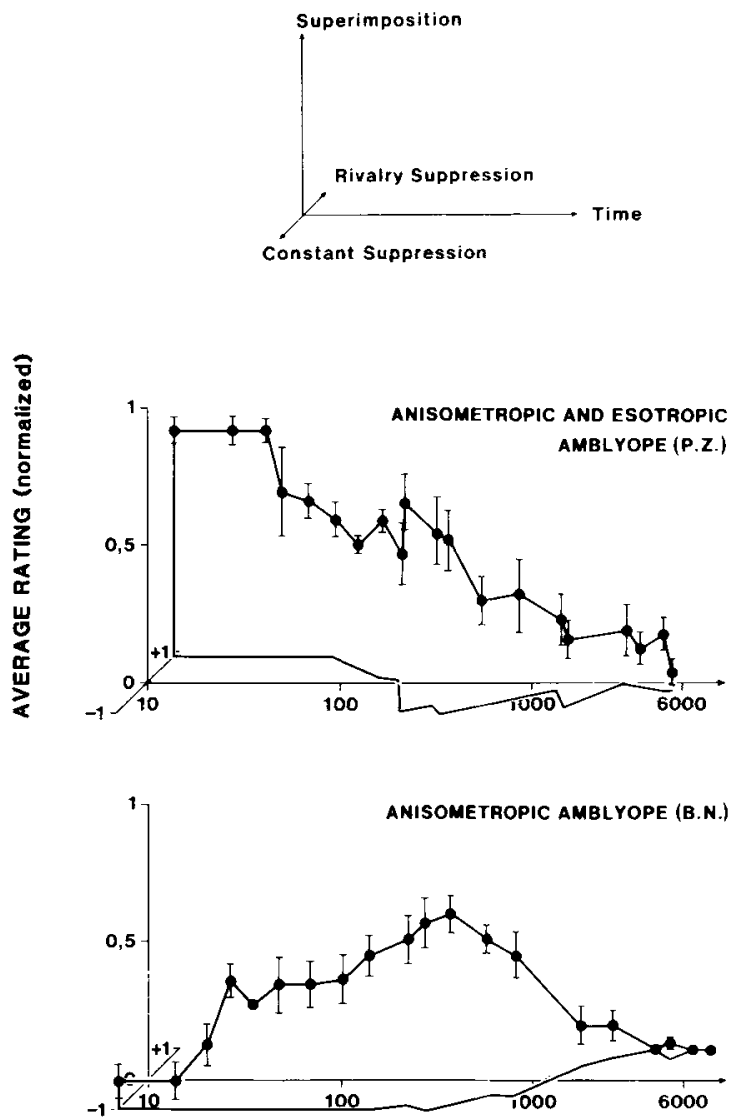
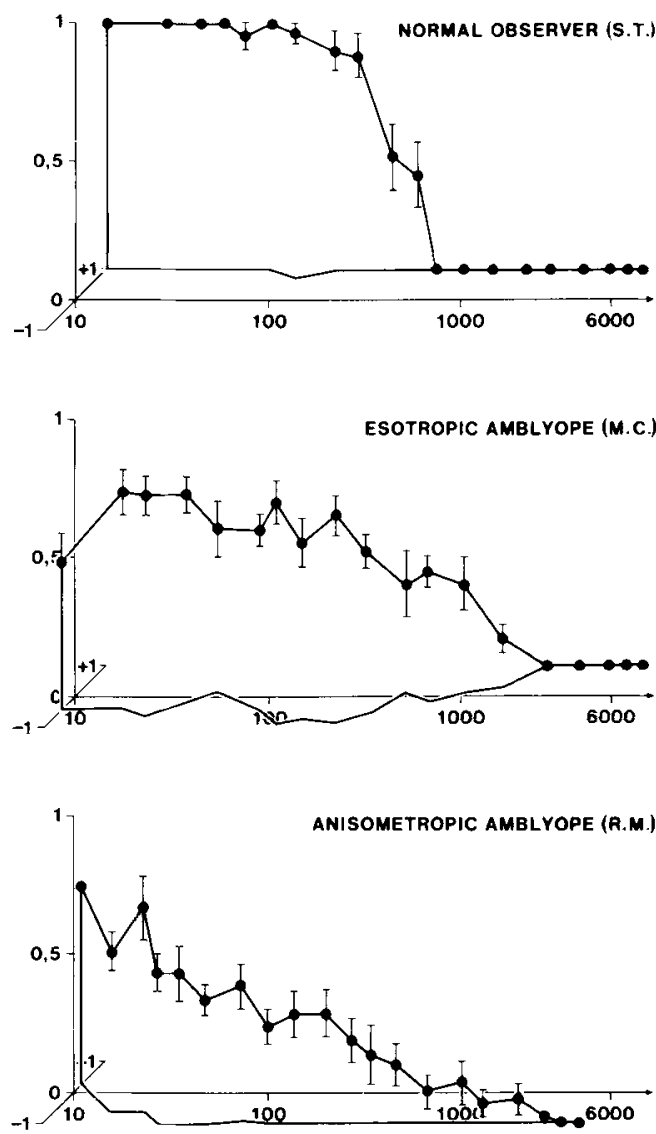

STIMULUS DURATION (ms)

Figure 3. Comparison of the time courses of suppression in different subjects without attenuation of one eye. One case from each group is shown. Plotted prints represent the mean of six ratings; bars show the standard deviation.

monocular images as superimposed (see Figure 4). With progressive attenuation, the dominance of the nonamblyopic eye decreased, and the onset of suppression was delayed. Longer stimulus presentations always resulted in complete rivalry of the two monocular images, even for Subject P.Z.

The data of Subject R.S., as shown in Figure 4, indicate that a very deep attenuation of the nonamblyopic eye (neutral density filter $6.5 \%$, red curve) can lead to a monocular dominance of the amblyopic eye's image, thus indicating the beginning of a reversal of eye dominance.

Group 2. Attenuation of the nonamblyopic eye in these subjects resulted in an immediate inversion of the relationship in dominance between the two eyes (Figure 4: yellow curve, left-eye dominant; other curves, right-eye dominant). Perception of the pattern presented to the nonamblyopic eye was progressively reduced, just as it was when the pattern was presented to the attenuated eye in normal observers (Figure 4). Long stimulus durations led to rivalry suppression, independently of the degree of attenuation. Attenuation of the amblyopic eye resulted in a further increase of the nonamblyopic eye's domi- nance. Nevertheless, no constant suppression resulted for long-lasting stimuli.

Group 3. In these subjects, attenuation of the dominant eye resulted in progressive superimposition of both eyes' images for short stimulus durations and rivalry for long stimulus presentations. For Subject B.N., as shown

Figure 4. (Opposite page) Interocular suppression in normal and amblyopic observers. Time courses of suppression under attenuation of one eye by neutral density filters (yellow, $100 \%$ luminancewithout attenuation; green, $51 \%$; blue, $32 \%$; purple, $16 \%$; red, $6.5 \%$ ). One case from each group is presented. Normal observers: short stimulus durations, progressive increase of dominance of the nonattenuated eye; longer stimulus durations, rivalry. Amblyopic observers (Group 1): short stimulus durations, superimposition; longer stimulus durations, decrease of the nonamblyopic eye's dominance, then rivalry. Amblyopic observers (Group 2), results similar to those for normal observers: short durations, progressive increase in dominance of the amblyopic eye; longer stimulus presentations, rivalry. Amblyopic observers (Group 3): short stimulus durations, progressive superimposition; longer stimulus durations, rivalry. Amblyopic observers (Group 4): short stimulus durations, progressive superimposition; stimulus durations longer than $5,000 \mathrm{msec}$, progressive rivalry alternations. 

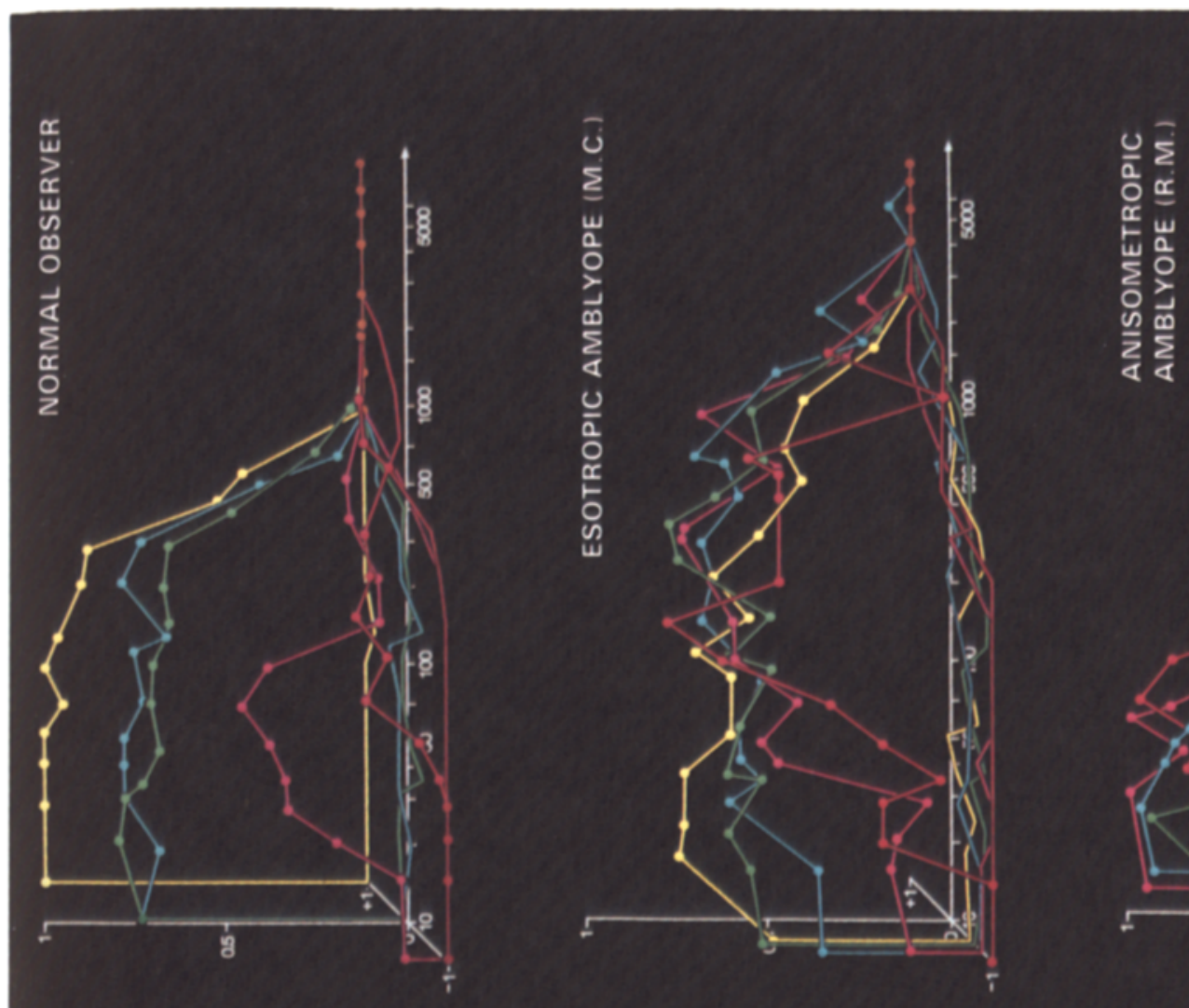

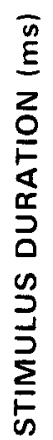
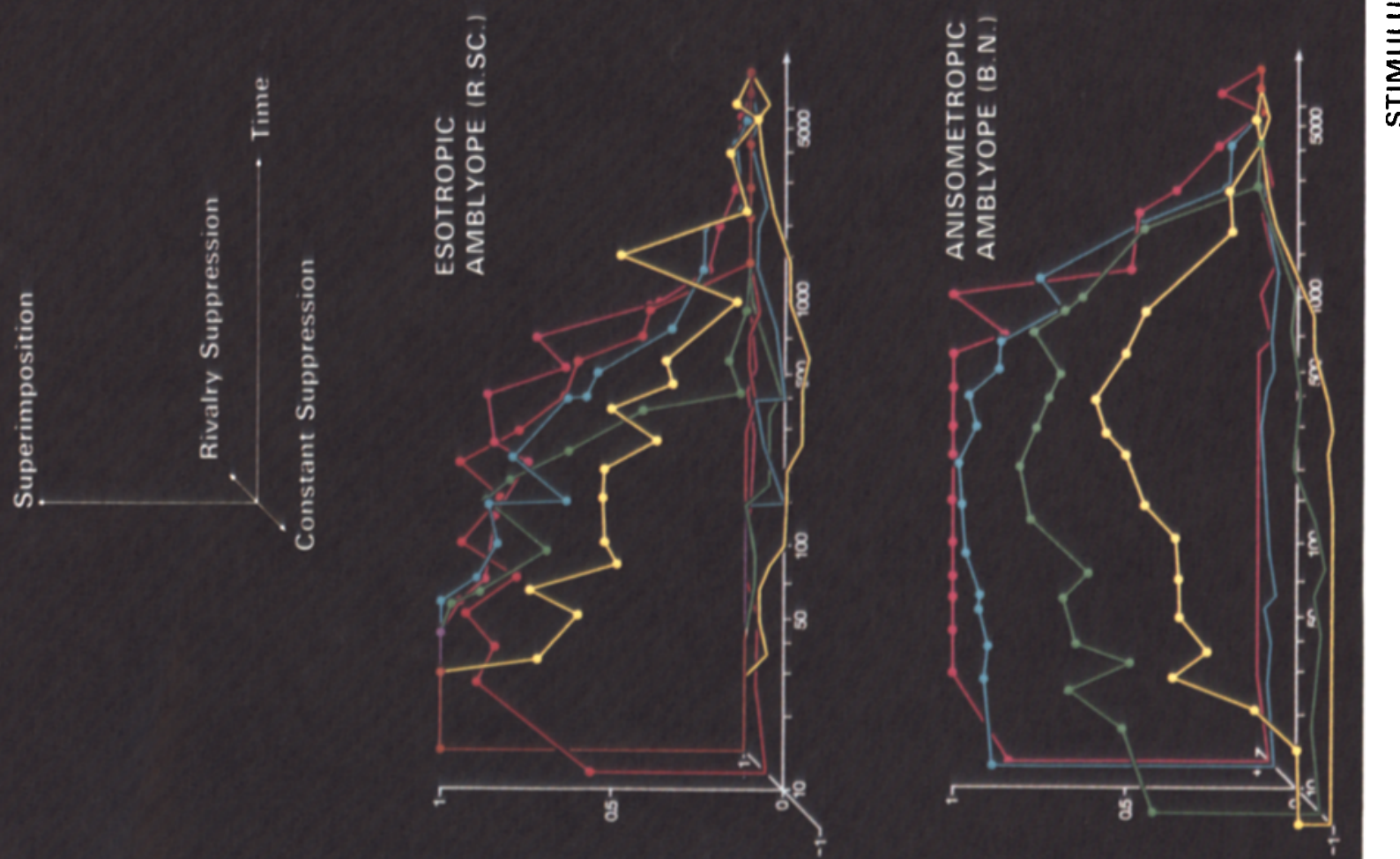

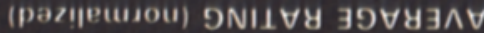

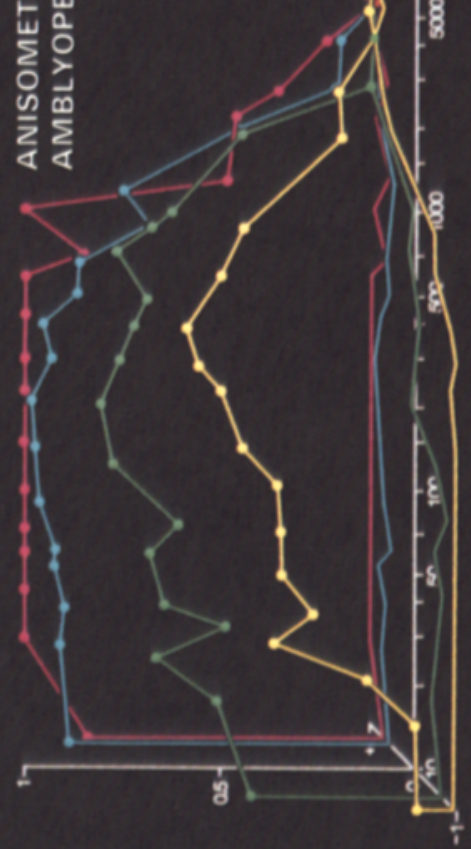


in Figure 4, a neutral density filter of $16 \%$ was sufficient to "reproduce" the time course of suppression seen in normal subjects. Further attenuation (neutral density filter $6.5 \%$ ) produced a reversal of dominance, with the amblyopic eye now being dominant (omitted from Figure 4, for clarity).

Group 4. In these subjects, attenuation of the nonamblyopic eye resulted in total superimposition of the two images, leading to a complete alternation between the two eyes (rivalry), but with a slight temporal dominance of the nonamblyopic eye (Figure 4).

\section{Comparison of the Groups}

A comparison of the groups suggests that all subjects, normal and amblyopic, produce suppression patterns belonging to one and the same family of curves. The amblyopic subjects in Group 3 show the reverse suppression pattern of normal subjects. The amblyopic subjects in Group 2 can be interpreted as intermediate between nor$\mathrm{mal}$ subjects and the amblyopic subjects in Group 3. Thus, for example, the time course of suppression of Subject M.C. (Group 2) without neutral density filters (yellow curve) looks similar to the time course of suppression in the normal Subject S.T. with attenuation of one eye by neutral density filter $32 \%$ (blue curve) or Subject B.N. (Group 3) with attenuation of the nonamblyopic eye by neutral density filter $51 \%$ (green curve). The time course of Subject P.Z. of Group 1 suggests that the suppression pattern in this group can be interpreted as an intermediate stage between normal subjects and the amblyopic subjects in Group 4, showing constant suppression without neutral density filters.

For long stimulus durations, there is one exception: whereas the suppression pattern in the subjects of Group 4 can be changed to "normal" by filters, the suppression pattern of normal subjects cannot be transformed into constant suppression (see the control experiments).

\section{Control Experiments}

Surprisingly, only the 2 subjects in Group 4 (R.M. and S.H.), out of 10 tested amblyopes, showed constant suppression for the longer lasting stimuli, although all subjects constantly suppressed the amblyopic eye under natural, everyday conditions. This raises the question of whether constant suppression can be elicited under our experimental conditions. As a control, we measured the time course of suppression of all amblyopes, while progressively attenuating the amblyopic eye.

As expected, this led to the further dominance of the nonamblyopic eye, so that, for short presentation times, all amblyopes finally showed suppression patterns as described for Group 3. For long stimulus presentations, with the exception of Subjects R.M., S.H., and sometimes also P.Z., even this attenuation of the amblyopic eye did not result in constant suppression.

\section{DISCUSSION}

\section{Relationship to Previous Studies}

In this paper, we have compared the time courses of interocular suppression in normal and amblyopic subjects. As already mentioned, we had to modify the rating scale used before by Wolfe (1986a) and de Belsunce and Sireteanu (1991). A third axis was added to quantify how much information from each eye was received during stimulus presentation. Thus, it became possible to distinguish between rivalry and constant suppression. Constant suppression is defined as the total invisibility of one grating over the whole presentation time ( $z$-axis, -1 ; see Figures 1 and 2). Binocular rivalry is defined as the complete alternation from one eye's image to the other, irrespective of the time the image presented to each eye is seen $(z$-axis, +1$)$. A temporal dominance of one eye cannot be discovered with this scale. Therefore, subjects were asked to describe their impressions of the alternation rate.

With this rating scale, we found that the temporal properties of suppression in normal and amblyopic subjects are different but related to each other. Subjects with normal vision showed superimposition of the two monocular images for short stimulus durations and binocular rivalry for durations longer than $150 \mathrm{msec}$, as described by Wolfe (1986a). In contrast with Wolfe (1986a), who found that in all normal subjects tested in his study, suppression required $150 \mathrm{msec}$ to become manifest, in our subjects the onset of rivalry suppression varied from 100 to $700 \mathrm{msec}$, but stayed constant within each subject.

Of our amblyopic subjects, most showed suppression patterns similar to those described by de Belsunce and Sireteanu (1991): Some amblyopes showed a time course of suppression similar to that of normal observers (Group 1 of de Belsunce and Sireteanu, 1991). Subject K.R. in our Group 1 would have been included in this group. The remaining subjects of de Belsunce and Sireteanu fell into two categories: one group showed a more rapid onset of suppression (about $80 \mathrm{msec}$ ), as in our subject R.SC., and the other showed a prevalence of the dominant eye for short exposure times, and then suppression or binocular rivalry, comparable to our Subjects B.N., J.KL., and U.L.

We found time courses of suppression not described by de Belsunce and Sireteanu (1991)-for instance in Subjects M.C. and B.PT., who showed incomplete superimposition for short presentation times, followed by rivalry for longer stimulus duration. The existence of these hitherto undescribed suppression patterns, as well as the difficulty of establishing clear-cut categories, suggests the existence of a continuous spectrum, rather than discrete groups.

\section{Evaluation of the Results}

The main aim of the present study was to test the hypothesis put forward by de Belsunce and Sireteanu (1991) 
that the observed differences between suppression patterns in normal and amblyopic subjects might be explained by the weakened information processing in the visual pathway of the amblyopic eye. This hypothesis seems to be substantiated by the data: as suggested by preliminary findings of de Belsunce and Sireteanu (1991), progressive attenuation of the image of one eye in normal observers with neutral density filters produces patterns of suppression similar to those found in the amblyopic observers.

Conversely, it was possible to reproduce the "normal" pattern of suppression by adding neutral density filters in the light beam of the nonamblyopic eye's stimulus. Each subject required a different density of the filter to reach a balance between the two eyes: no filter for subjects in Group 1, weak filters for Group 2, moderate filters for Group 3, and very dense filters for the subjects in Group 4. Also, at least for short presentation times, attenuation of the amblyopic eye's image seems to "transform" all subjects into subjects belonging to Group 3 .

Thus, at least under mesopic conditions, it seems that depth of suppression in each subject can be characterized by the amount of attenuation of the dominant eye's stimulus needed to generate a rivalrous suppression pattern. Indeed, the heterogeneity of the suppression patterns of the amblyopic subjects tested in this study can be interpreted as expressions, differing in strength, of an imbalance in image processing between the amblyopic and the nonamblyopic eye.

As in the study of de Belsunce and Sireteanu (1991), it was not possible to establish a clear relationship between depth or pattern of suppression and the kind of sensory disturbance or the depth of amblyopia of each subject. There was no clear-cut difference between strabismic and anisometropic amblyopes. Neither did we find the inverse correlation between depth of suppression and amblyopia, proposed by Holopigian et al. (1988). This lack of agreement may be due to the fact that suppression probably was established during the early developmental period and changed to adapt to the present binocular status. In subjects with deep amblyopia, suppression might be found only as a relict, since its purpose (avoidance of double images) has been attained.

Before concluding that constant suppression in amblyopes is firmly related to the alternating suppression seen in binocular rivalry, one caveat is in order: under our experimental conditions, all but 2 amblyopes showed rivalry for longer lasting stimuli, although all constantly suppress their amblyopic eye during normal everyday conditions. This can be explained by the choice of orthogonal stimuli, which favors rivalry rather than strabismic suppression (Schor, 1977), and by the low luminance of our stimuli, a condition that also reduces suppression (Awaya et al., 1968; Hayashi, 1969; von Noorden \& Leffler, 1966). Thus, although the suppression measured in our amblyopic subjects seems to be related to binocular rivalry, the constant suppression that prevents diplopia in the everyday life of these subjects might include additional, and probably different, neural mechanisms.
There are several models for the possible localization of rivalry suppression in the human visual pathway, especially in relationship to other psychophysical phenomena (Blake, 1989; Lehky, 1988; Mueller, 1990; Wolfe, 1986b). These findings place the neural site of contour rivalry at a level that usually exhibits binocular fusionthat is, in the primary visual cortex. Psychophysical experiments in amblyopes suggest that constant suppression occurs at or after the site of pattern adaptation, which is known to be the striate cortex (Hess, 1991). Preliminary physiological results in strabismic monkeys indicate a site of constant suppression in V1 (Thiele, Bremmer, \& Hoffmann, 1992), but nothing is known about the specific neural mechanisms involved in this function.

Rivalry suppression might have played an important role in the development of constant suppression and amblyopia. Presumably, an early squint causes rivalry. To remove this unpleasant percept (Birch, Shimojo, \& Held, 1985; Shimojo, Bauer, O'Connell, \& Held, 1986; Held, personal communication, 1991), one of the two nonfusable stimuli is suppressed constantly by the other (in some instances, alternating fixation may occur). Perceptually, this leads to a loss of acuity and binocularity (Sireteanu \& Fronius, 1981; Sireteanu, Fronius, \& Singer, 1981), and also a disturbance in the intrinsic geometric relationships of the suppressed eye (spatial distortion: Bedell \& Flom, 1981; Fronius \& Sireteanu, 1989; Hess, Campbell, \& Greenhalgh, 1978; Lagrèze \& Sireteanu, 1991).

\section{REFERENCES}

Anderson, J. D., Bechtoldt, H. P., \& Dunlap, G. L. (1978). Binocular integration in line rivalry. Bulletin of the Psychonomic Society, 11, 399-402.

Awaya, S., Tanabe, S., \& Ueda, W. (1968). On visual acuity of amblyopic eye under binocular conditions: I. Anisometropic hypermetropic amblyopia. Acta Societatis Ophthalmologicae Japonicae, 72 , 535.

Bedell, H. E., \& Flom, M. C. (1981). Monocular spatial distortion in strabismic amblyopia. Investigative Ophthalmology \& Visual Science, 20, 263-268.

Birch, E. E., Shimojo, S., \& Held, R. (1985). Preferential looking assessment of fusion and stereopsis in infants aged 1 to 6 months. Investigative Ophthalmology \& Visual Science, 26, 366-370.

BLAKE, R. (1989). A neural theory of binocular rivalry. Psychological Review, 96, 145-167.

BOKANDER, J. (1966). The importance of collative-affective and intensive arousal potential in stereoscopically induced conflict. Scandinavian Journal of Psychology, 7, 234-238.

BOWER, T. G. R., \& HALEY, L. J. (1964). Temporal effects in binocular vision. Psychonomic Science, 1, 409-410.

Breese, B. B. (1899). On inhibition. Psychological Monographs, 3, $1-65$.

DALE, R. T. (1982). Fundamentals of ocular motility and strabismus. New York: Grune \& Stratton.

De Belsunce, S., \& Sireteanu, R. (1991). The time course of interocular suppression in normal and amblyopic subjects. Investigative Ophthalmology \& Visual Science, 32, 2645-2652.

DuKe-Elder, S., \& WYBAR, K. (1973). Systems of Ophthalmology, 6, London: Kimpton.

DuTour, E. F. (1760). Pourquoi un objet sur lequel nous fixons les yeux, paroit-il unique? Memoires de Mathematique et de Physique tirés des registres de l'Academie Royale des Sciences, Paris, 4, 499-511. 
FAHLE, M. (1983). Non-fusable stimuli and the role of binocular inhibition in normal and pathological vision, especially strabismus. Documenta Ophthalmologica, 55, 323.

Fronius, M., \& Sireteanu, R. (1989). Monocular geometry is selectively distorted in the central visual field of strabismic amblyopes. Investigative Ophthalmology \& Visual Science, 30, 126-136.

Goldstein, A. G. (1970). Binocular fusion and contour suppression. Perception \& Psychophysics, 7, 28-32.

HaAse, W., \& Goossens, H. (1984). Latency (P2) of the transient response (VECP) in different types of amblyopia. In R. D. Reinecke (Ed.), Proceedings of the Intermational Strabismological Association (pp. 173-189). New York: Grune \& Stratton.

Hamasaki, D. J., \& FlynN, J. T. (1981). Amblyopic eyes have longer reaction times. Investigative Ophthalmology \& Visual Science, 21, 846-853.

HAYASHI, H. (1969). A study of visual acuity under binocular conditions. Acta Societatis Ophthalmologicae Japonicae, 73, 507.

Helmholtz, H. voN (1867). Handbuch der physiologischen Optik. Leipzig: L. Voss.

HeRING, E. (1920). Handbuch der Augenheilkunde: 4. Schlußlieferung. Berlin: Springer-Verlag.

Hess, R. F. (1991). The site and nature of suppression in squint amblyopia. Vision Research, 31, 111-117.

Hess, R. F., Campbell, F. W, \& Greenhalgh, T. (1978). On the nature of the neural abnormality in human amblyopia: Neural aberrations and neural sensitivity loss. Pflügers Archiv, 377, 201-207.

Holopigian, K., Blake, R., \& Greenwald, M. J. (1988). Clinical suppression and amblyopia. Investigative Ophthalmology \& Visual Science, 29, 444-451.

KaUfManN, L. (1963). On the spread of suppression and binocular rivalry. Vision Research, 3, 401-415.

LaGRèze, W. D., \& SireteanU, R. (1991). Two-dimensional spatial distortions in human strabismic amblyopia. Vision Research, 31, 1271-1288.

LEHKY, S. R. (1988). An astable multivibrator model of binocular rivalry. Perception, 17, 215-228.

LeONARDS, U., SiReTEANU, R. (1991). Interocular suppressioncomparison between binocular rivalry in normal subjects and constant suppression in amblyopic subjects. Perception, 20, 135(A73a).

LEVELT, W. J. M. (1965). On binocular rivalry. Soesterberg: Rep. Institute for Perception RVO-TNO.

MUELLER, T. J. (1990). A physiological model of binocular rivalry. Visual Neuroscience, 4, 63-73.

PANUM, P. L. (1858). Physiologische Untersuchungen über das Sehen mit zwei Augen. Kiel: Schwerssche Buchhandlung.
SChOr, C. (1977). Visual stimuli for strabismic suppression. Perception, 6, 583-593.

Shimojo, S., Bauer, J. A., O'Connell, K. M., \& Held, R. (1986). Prestereoptic binocular vision in infants. Vision Research, 26, 505-510.

Sireteanu, R., \& Fronius, M. (1981). Naso-temporal asymmetries in human amblyopia: Consequence of long-term interocular suppression. Vision Research, 21, 1055-1063.

Sireteanu, R., Fronius, M., \& Singer, W. (1981). Binocular interaction in the peripheral visual field of humans with strabismic and anisometropic amblyopia. Vision Research, 21, 1065-1074.

Sireteanu, R., \& Singer, W. (1980). The "vertical effect" in human squint amblyopia. Experimental Brain Research, 40, 354-357.

Smith, E. L., LeVi, D. M., ManNy, R. E., Harwerth, R. S., \& WHITE, J. M. (1985). The relationship between binocular rivalry and strabismic suppression. Investigative Ophthalmology \& Visual Science, 26, 80-87.

Thiele, A., Bremmer, F., \& Hoffmann, K. P. (1992). Rhythmogenesis in Neurons and Networks. In N. Elsner \& D. W. Richter (Eds.), Proceedings of the 20th Göttingen Neurobiology Conference (Abstract 345). Stuttgart: Thieme.

VON NoORDEN, G. K. (1961). Reaction time in normal and amblyopic eyes. Archives of Ophthalmology, 64, 817.

VON NOORDEN, G. K. (1990). Binocular vision and ocular motilityTheory and management of strabismus (E. A. Klein, Ed., pp. 200208). St. Louis: Mosby.

Von Noorden, G. K., \& Burian, H. M. (1960). Perceptual blanking in normal and amblyopic eyes. Archives of Ophthalmology, 64, 817.

Von Noorden, G. K., \& LefFler, M. B. (1966). Visual acuity in strabismic amblyopia under monocular and binocular conditions. $A r-$ chives of Ophthalmology, 76, 172-177.

WADE, N. J. (1973). Binocular rivalry and binocular fusion of afterimages. Vision Research, 13, 999-1000.

WOLFE, J. M. (1983). Influence of spatial frequency, luminance, and duration on binocular rivalry and abnormal fusion of briefly presented dichoptic stimuli. Perception, 12, 447-456.

WolfE, J. M. (1986a). Briefly presented stimuli can disrupt constant suppression and binocular rivalry suppression. Perception, 15, 413.

Wolfe, J. M. (1986b). Stereopsis and binocular rivalry. Psychological Review, 93, 269-282.

(Manuscript received July 8, 1992; revision accepted for publication December 18, 1992.) 